\title{
DESORPTION AND USE OF SATURATED LIGHTWEIGHT AGGREGATE IN INTERNAL CURING
}

\section{ABSTRACT}

Roughly 20 years ago there was a brand new concrete-curing concept presented in the U.S. based on providing "extra curing" water from inside the concrete. The extra water shoul be added to concrete during mixing, but is bound to some kind of carrier, so it does not alter the water-cement ratio. This technique, known as Internal Curing (IC) keeps the cement paste moist from the first moment when it normally would start to desiccate and is not mature enough to apply conventional means of curing. The durability and effectiveness of IC depend on the boundary conditions at the site as well as the properties of the carrier - in this case, Lightweight Aggregate (LWA), which, after the water soaking, replaces some part of the Normalweight Aggregate (NWA). This work deals with LWA (available on the European market) in the context of its properties affecting the efficiency of IC.

\section{INTRODUCTION}

\subsection{Internal Curing}

Internal curing (IC) is a means of curing which provides extra water from tiny "reservoirs" inside concrete to keep the cement paste moist and assures the highest possible degree of hydration ( $\alpha$ ) (Henkensiefken, et al., 2010; Briatka, 2010). This means extra water is to be added when mixing concrete. To avoid increasing the water-cement ratio $(\mathrm{w} / \mathrm{c})$, the extra water must not be free - it must be fixed in some kind of carrier (Briatka, et al., 2010). Many kinds of such carriers exist. The essential presumption is that the carrier has a suitable porosity, absorptivity and a grading curve essential for the correct spacing in the fresh mixture. Basically, the carrier must be able to absorb water, but in concrete when cement paste tends to dry out due to either inner or outer desiccation (simply, all the known shrinkage mechanisms), it must release water accordingly. With the falling relative humidity of (initially) fully saturated cement paste caused by autogenous consumption for hydration as well as exposure to environmental conditions ( $\mathrm{RH}$; T, wind velocity $\mathrm{v}_{\mathrm{W}}$ ) (Briatka, et al., 2010), the carrier's pores start to empty to avoid the creation of voids in the cement paste. In this way the capillary stresses $\mathrm{P}_{\mathrm{CAP}}(\mathrm{Pa})$ are to be generated and raised following the formula (1) derived from Kelvin's and Young-Laplace equations (Wittmann, 1976; Henkensiefken, 2008), where $\mathrm{R}$ is the universal gas constant $(8.314 \mathrm{~J} / \mathrm{mol} . \mathrm{K})$; $\mathrm{T}(\mathrm{K})$ is the temperature, $\mathrm{RH}(\%)$ is the internal relative humidity, and $\mathrm{V}_{\mathrm{m}}\left(\approx 18.10^{-6} \mathrm{~m}^{3} / \mathrm{mol}\right)$ is the molar volume of the pore solution (fig. 1). 


$$
P_{C A P}=\frac{R \cdot T \cdot \ln \left(\frac{R H}{100}\right)}{V_{m}}(\mathrm{~Pa})
$$

Then the driving force of IC may be clarified on the basis of the capillary tension described by the Young-Laplace equation (formula 2), where $\gamma$ (et $296.5 \mathrm{~K}=0.07243 \mathrm{~N} / \mathrm{m}$ ) is the surface tension of the pore fluid, and $\theta$ - (assumed to be $0 \mathrm{rad}$ ) is the liquid-solid contact angle, which says that by increasing the $\mathrm{P}_{\mathrm{CAP}}$ (decreasing the $\mathrm{RH}$ ), the radius of the emptied capillaries $r_{\mathrm{CAP}}(\mathrm{m})$ decreases altogether. In other words, the biggest pores (capillaries) empty first, and the smaller ones start right after that - in order of the radii (fig. 2) (Radlinska, et al., 2008). When considering that the carrier's pores are larger than those in the cement paste, we can draw the conclusion that the cement paste remains saturated and that the curing works.

$r_{C A P}=-\frac{2 \cdot \gamma \cdot \cos (\theta)}{P_{C A P}}(\mathrm{~m})$

One of the possible carriers is based on expanded shale (generally, clayey rocks) with low density, high porosity and a rigid skeleton

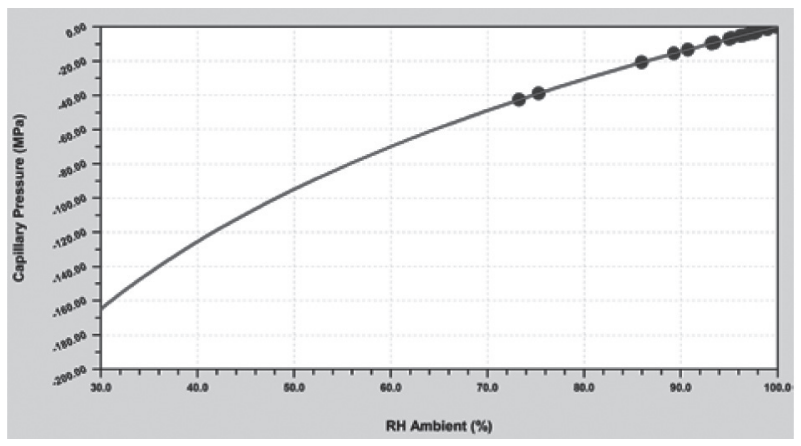

Fig. 1 Capillary pressure $P_{C A P}$ as a function of the $R H$.

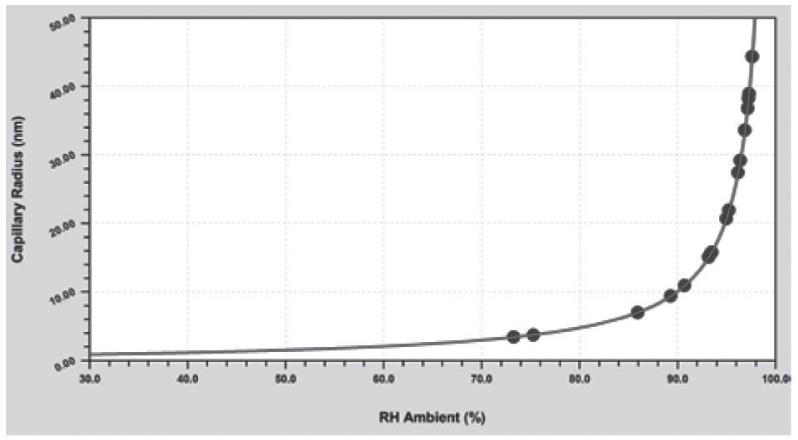

Fig. 2 Capillary radius $r_{C A P}$ as a function of the $R H$.

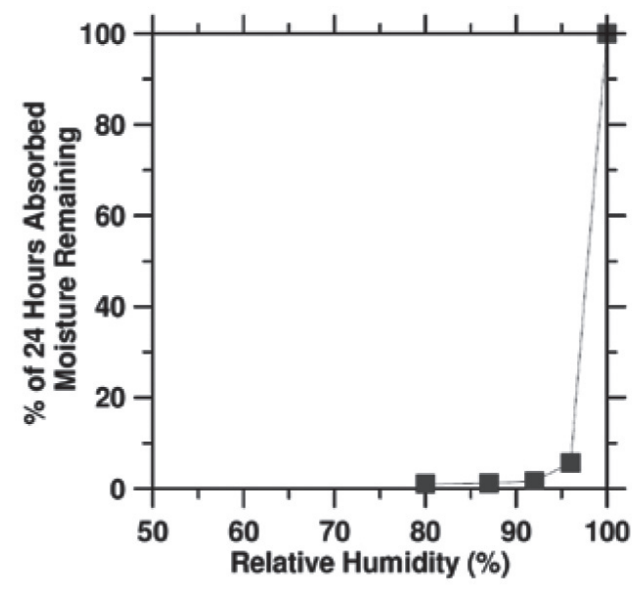

Fig. 3 Desorption curve of SLWA (Radlinska, et al., 2008).

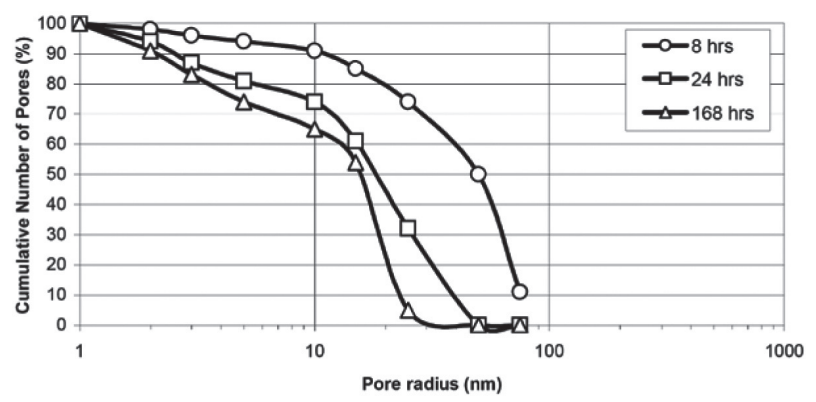

Fig. 4 Pore size distribution (Micro Intrusion Porosimetry) for cement paste $(w / c=0.3)$ at three different ages (modified from Henkensiefken, 2008).

- well known as light-weight aggregate (LWA). The LWA, by reduction of the cement paste's porosity and by keeping the w/c low, while possibly raising $\alpha$, enables us to produce dense concrete structures with high strength. Many authors (e.g. Bentz, et al. 2005), who deal with IC by using SLWA, base their works on one plot (fig. 3) showing a desorption curve of the SLWA used in the U.S. However, as we all know, the materials are not of the same origin. Therefore variations in the results may be expected. Therefore, this paper is devoted to researching the possibility of using LWA in the European concrete and construction markets.

\subsection{Significance of Research}

The significance of curing is directly proportional to the significance of the concrete structure itself as well as the required strength (related to a low w/c) and surface modulus (ratio of the surface exposed to the environment to the volume of the structure). The 


\section{IDYALS JOUSSIAL

whole concept of internal curing (as many authors have already presented) is much more suitable for large, flat high-strength concrete structures than for the usual concreting jobs (Briatka, 2010; Briatka, et al., 2010). The fundamental problem is that within these structures, the most severe conditions usually meet at one spot all at once. A flat structure with a high surface modulus normally hinders the protection of the structure at a very early age against water loss, the rate of which depends on $\mathrm{RH}, \mathrm{T}, \mathrm{v}_{\mathrm{W}}$ and, last but not least, sun radiation and the coefficient of the surface radiating absorptivity (Briatka, et al., 2010). On the other hand, when the internal curing is designed to protect the concrete at a very early age rather than later, after this critical period, the concrete self-desiccates and lacks water to complete hydration, which may lead to stopping the hydration as the surface layer is too dense (not permeable enough) to let the curing water (from watering) penetrate to the core zone (Sant, et al. 2010; Henkensiefken, 2008; Lura, 2003). Though unlike conventional curing concepts, the IC has to be defined and designed prior to mixing fresh concrete, so what we definitely need to know is the behavior of the specific LWA in IC. As such, we need to define three main parameters: (1) The volume of water available for IC (absorption), (2) the ability of the water to leave the SLWA when it is needed for IC (desorption) and (3) the distribution of the SLWA in concrete (Henkensiefken, 2008). This work mostly deals with the first two parameters as distribution is still somewhat also dependent on the mixture's composition.

\section{EXPERIMENTAL PART}

The tests were designed to investigate one of the dominant characteristics of SLWA which is inverse to absorptivity, i.e., desorption. The desorption of SLWA is a key parameter in the sense of SLWA's ability to supply drying cement paste with curing water via suction from saturated capillaries drawn by stresses higher than $\mathrm{P}_{\mathrm{CAP}}$ (Lura, 2003; Adamson, et al., 1997). In relation to the $\mathrm{RH}$ of the environment to which the samples are being exposed and the grading curve affecting the specific surface area (SSA) of each fraction, we focused on deriving a model for the desorption of SLWA, which would be helpful for the implementation of IC by SLWA in practice. In this way we also obtained a distribution curve of the capillaries in the order of the capillary radii. By comparing these distribution curves to the distribution curves of the pores in hardened cement paste, we aimed at evaluating the fitness of each sample (fraction) of the LWA for intended use in IC with regard to specific concrete and field conditions or at least assessing the need for supplementary curing by another means.

The experimental part consisted of several specific tests on material properties such as bulk density and density, the grading curve and the 24-hour absorptivity of the water. The results of these tests are presented hereinafter as supplementary data for a precise description of the material and its suitability in terms of absorption (water potentially available for curing) and desorption (water actually available for curing).

\subsection{Materials}

For the tests, three different fractions of LWA available on the European market under the brand name "Liapor" were chosen. All of these fractions were of the same chemical composition (all given in $\%$ by weight with $\pm 5 \%$ tolerance): $\mathrm{SiO}_{2} 55, \mathrm{Al}_{2} \mathrm{O}_{3} 24, \mathrm{Fe}_{2} \mathrm{O}_{3} 14$, $\mathrm{CaO} 5$, trace oxidex $2 \pm 2$. Liapor is a rotary kilned expanded shale (at $1090-1200{ }^{\circ} \mathrm{C}$ ) with a sintered surface. During the selection special attention was paid to an open versus a closed pore system as different fractions were made with or without grinding at the end. Also, the fineness of each fraction as well as its bulk density, density and 2-hour absorptivity were taken into account. Of course, even the characteristics related to the durability of the final concrete structure, e.g., maximum chloride content, maximum overall sulfur

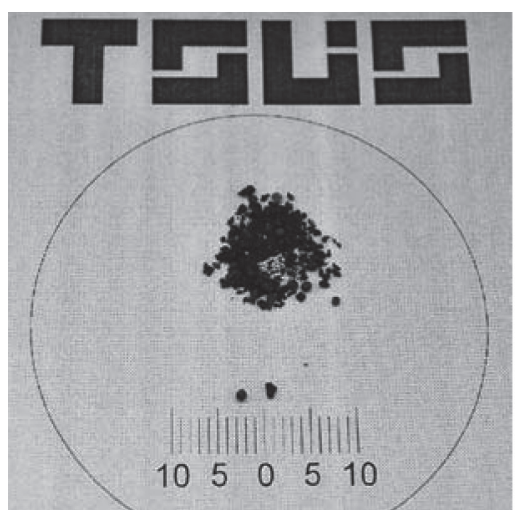

Fig. 5 Fraction 0/1 mm

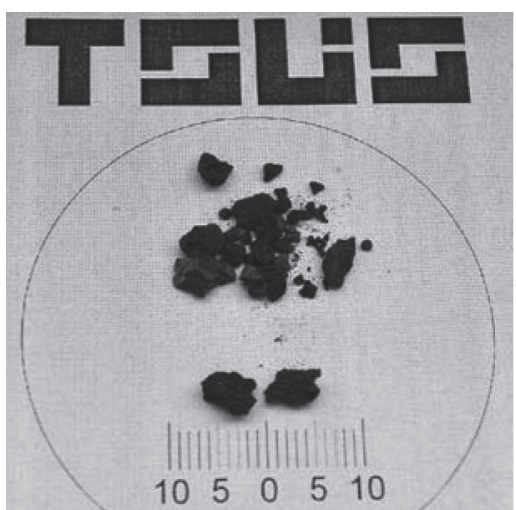

Fig. 6 Fraction 0/4 $\mathrm{mm}$.

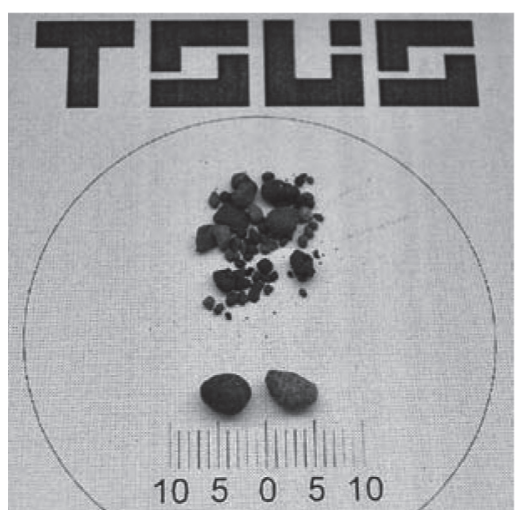

Fig. 7 Fraction $1 / 4 \mathrm{~m}$. 
content or resistance to alkali-silica reaction, were not ignored. Three fractions of LWA were chosen. They were denoted in accordance with EN 12620 and EN 13055-1 as a fraction of the diameter of the smallest grain (sieve opening) and the biggest grain as shown in pictures 5, 6 and 7 .

\subsection{Supplementary tests}

The tests on bulk density and density were performed in accordance with EN 1097-3 and EN 1097-6. The grading curves of the selected fractions were investigated according to the procedure for EN 9331. Within this supplementary phase the absorption capacity of the samples was tested according to EN 1097-6. The results and material properties are shown in table 1 and fig. 8 .

\subsection{Preparation of Samples}

The samples used for measuring the desorption were prepared by separately soaking the individual fractions in water at a constant temperature of $20 \pm 2^{\circ} \mathrm{C}$. After $24 \pm 2$ hours of soaking, the decanted water was poured off, and the moisture on the surface of the SLWA was dried using paper towels. To determine if all the surface water had been removed, a simple approach using a control paper towel was used. Then the specimens weighing in a range of circa $20 \mathrm{~g}-$ $25 \mathrm{~g}$ were batched into small plastic cylinders (Ø $50 \mathrm{~mm}$; height 25 $\mathrm{mm}$ ) with the upper side open.

Three tests were performed on the three individual sets of samples. One sample set represented 8 specimens (cylinder bowls) of each of the three fractions, i.e., 24 specimens.

Tab. 1 Summary of testing of supplementary material.

\begin{tabular}{|l|c|c|c|}
\hline Parameter (unit) & $\mathbf{0 / 1}$ & $\mathbf{0} / \mathbf{4}$ & $\mathbf{1 / 4}$ \\
\hline Bulk Density $\left(\mathrm{kg} / \mathrm{m}^{3}\right)$ & 610 & 410 & 760 \\
\hline Density $\left(\mathrm{kg} / \mathrm{m}^{3}\right)$ & 1690 & 1090 & 1210 \\
\hline Absorptivity (\%) & 4,73 & 7,16 & 14,39 \\
\hline
\end{tabular}

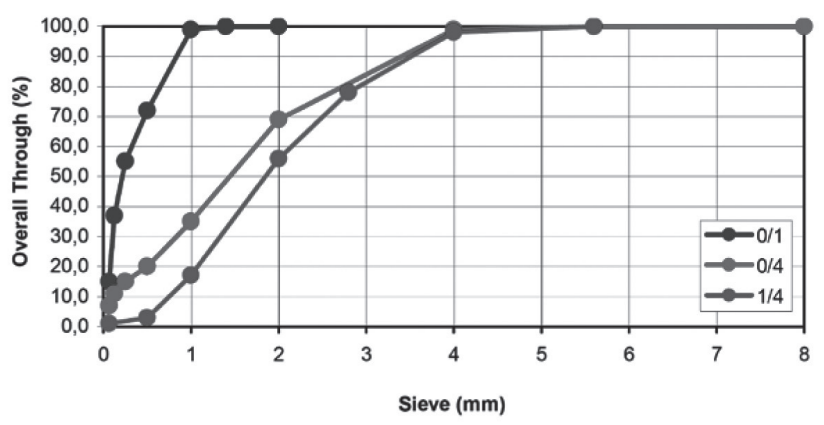

Fig. 8 Grading curves of the testing samples.

\subsection{Testing procedure}

The prepared specimens were put into a simple environmental chamber where constant $\mathrm{RH}, \mathrm{T}$ (around $23.5{ }^{\circ} \mathrm{C}$ ) and negligible $\mathrm{v}_{\mathrm{W}}$ were mainatined. The environment inside the chamber was regulated by the simple principle of the equilibrium state of an isolated system. In our case the isolated system was represented by an open water level with the air above. After some time these two substances achieved an equilibrium of RH $100 \%$. When it was necessary to regulate the $\mathrm{RH}$, a slight degree of air pressure was enabled in the chamber through the adjustable louvre in the top glass table. The louvre was calibrated prior to the tests. During the tests, data on the $\mathrm{RH}$ and both the air and water temperature were continuously captured. The specimens were regularly weighed on scales with an accuracy of $\pm 0.0005 \mathrm{~g}$. This degree of accuracy was needed since the initial weight of the absorbed water might vary around $0.9 \mathrm{~g}$ per sample. When zero weight loss was measured between two subsequent weighings, the RH in the environmental chamber was altered downward, and the test continued in the same way. The tests were adjusted for 8 equilibrium states plus the very first measurement and the very last one, when the sample was exposed to a low RH (below $30 \%$ ) using silica gel.

\section{RESULTS AND DISCUSSION}

A total of three tests of an overall duration of around 70 days were performed. They were performed on 72 specimens (24 for each fraction), which gave us 696 datapoints (232 for each fraction) to be analyzed.

\subsection{Supplementary tests}

Out of all the supplementary tests one important parameter closely associated with the grading curve and particle size distribution arose. The parameter in question - the specific surface area (SSA) - must be one of the most critical in the loss of water to the environment on a solid-air interface. From the particle size distribution curves and based on the assumption that the particles are of an ideal spherical shape, we calculated the individual SSA for each fraction (fig. 9) and the specific SSA for particular grain sizes (fig. 10).

\subsection{Desorption}

The following plots (figs. 9 - 11) show the desorption (water loss) of the SLWA. The plots comply with their expected behavior as the driving force of desorption is mainly the RH of the environment with which the RH of the SLWA tends to get in equilibrium. The function 


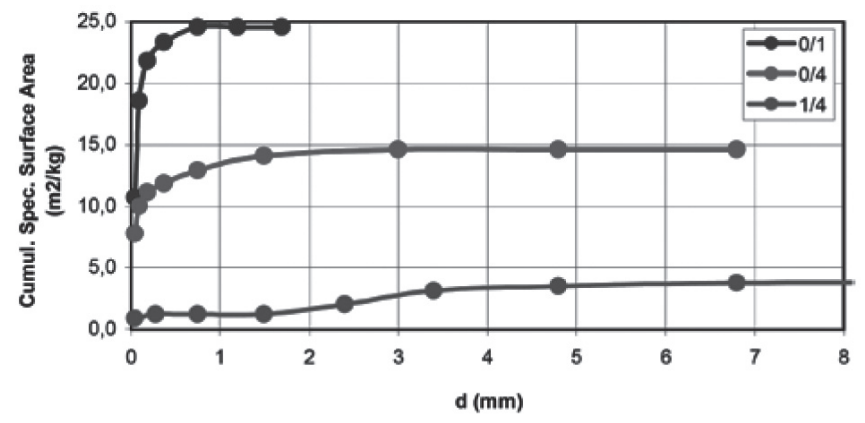

Fig. 9 Cumulative curve of the specific surface area $\left(\mathrm{m}^{2} / \mathrm{kg}\right)$.

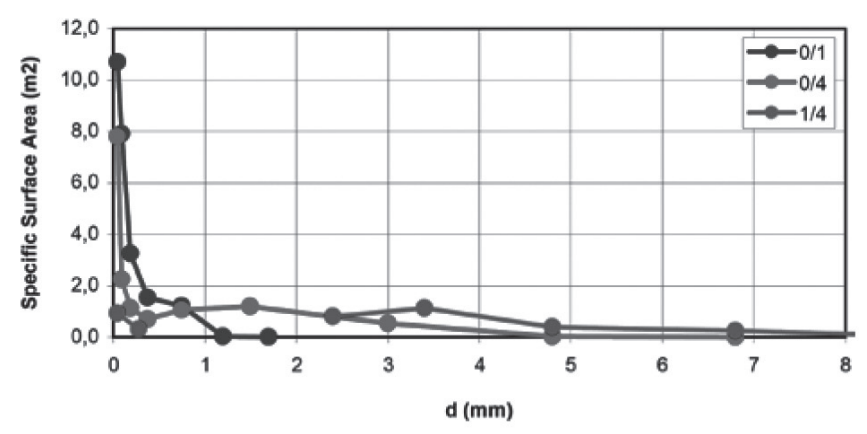

Fig. 10 Distribution curve of the specific surface area $\left(\mathrm{m}^{2} / \mathrm{kg}\right)$.

describing all the desorption curves obtained at a constant $\mathrm{T}(296.5 \mathrm{~K})$ and $\mathrm{v}_{\mathrm{W}}$ must be some variation of the power model. Even though it sounds simple, however, there are some particularities that should not be omitted. When a closer look is taken at all the plots, regardless of the fraction, all the curves approach zero around $\mathrm{RH} 40 \%$, which is denoted as the critical point (with a corresponding $\mathrm{P}_{\mathrm{CAP}}$ around $125 \mathrm{MPa}$ ) when the menisci in the capillaries break down, because the capillary radius of the emptying pores reaches circa $1.1556 \mathrm{~nm}$ (equal to 3 molecules of water) (Radlinska, et al., 2008; Adamson, et al., 1997). This means that the function will be defined just for the interval of RH $(40 \% ; 100 \%)$. Among the results, there were some slight variations, which most likely could be attributed to granularity (especially fineness) and pore structure (the sintered surface) of the LWA, affecting the whole scale of the parameters. One more important fact should be emphasized. Trying to dry out the surface of fine fractions with open-porosity grains is practically impossible, despite checking the surface moisture with the paper towel method. This led to an excess of the initial RH of the SLWA in some cases of more than $5 \%$. Along this note another observation is related that the desorption curves of finer fractions are steeper and that all the curves intersect at around $97 \%$ of the ambient $\mathrm{RH}$, which indicates that below $97 \% \mathrm{RH}$, no surface moisture is still present.

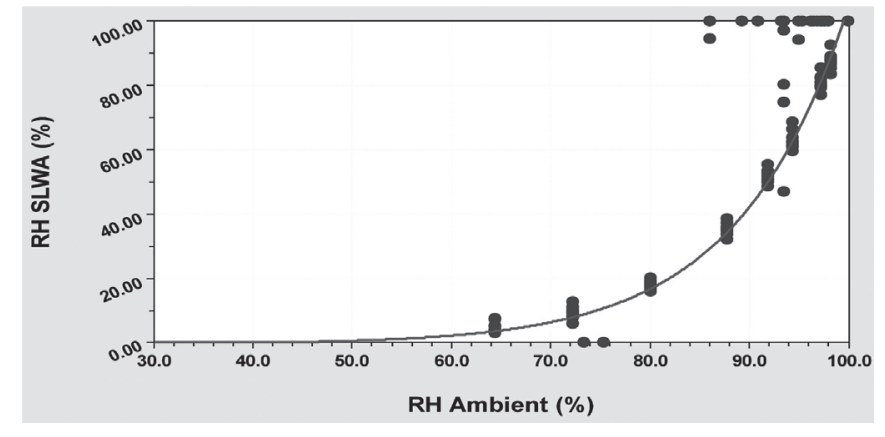

Fig. 11 Desorption curve - fraction 0/1.

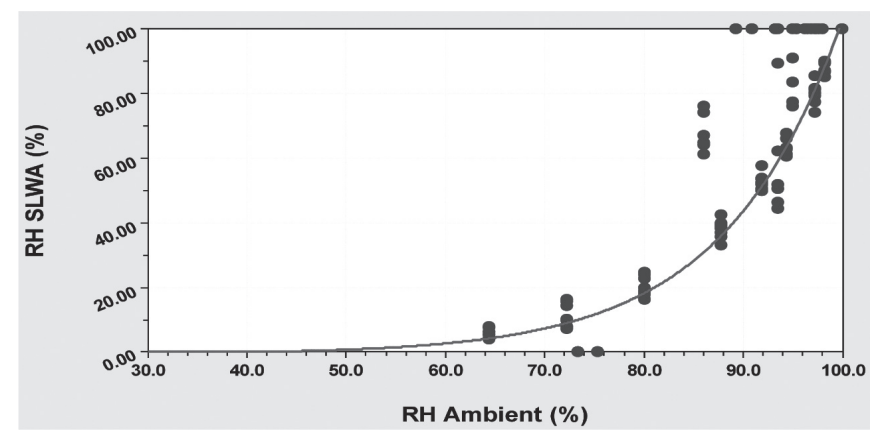

Fig. 12 Desorption curve - fraction 0/4.

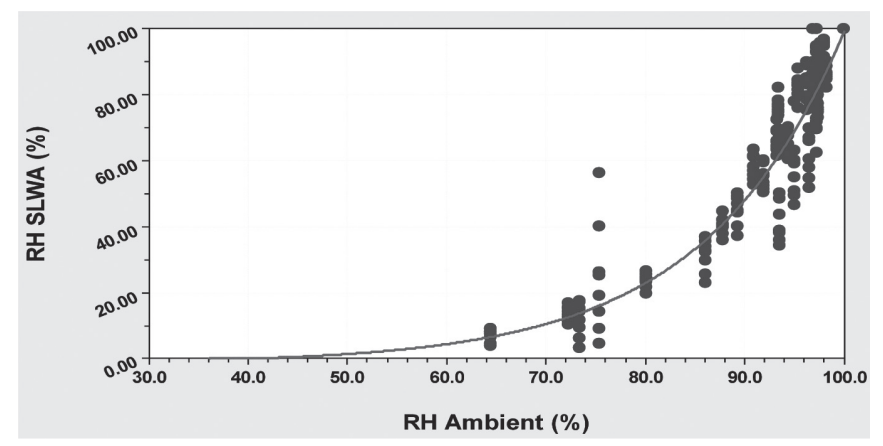

Fig. 13 Desorption curve - fraction 1/4.

Through the analysis of the captured data, we drew a conclusion in the form of the desorption model of the SLWA of at least Liapor $\mathrm{RH}_{\text {SLWA }}(\%)$. The desorption model, as shown by equation 3, is a power function based on the relative humidity of the environment $\mathrm{RH}_{\mathrm{AMB}}(\%)$ with which the SLWA has a tendency to get in equilibrium. The model also contains one corrective constant of a value of 4.38 , assuring that the function equals zero at $40.03 \% \mathrm{RH}_{\mathrm{AMB}}$ when there is no longer any removable water in the capillaries. The rate of desorption is further affected by the 
RH-dependent power of SSA $\left(\mathrm{m}^{2} / \mathrm{kg}\right)$. The power of SSA matches the divergence of the particular fractions in terms of the unavoidable initial surface moisture.

$$
R H_{S L W A}=\left(R H_{A M B}^{\frac{R H_{A M B}}{100}}-4.380\right) \cdot S S A^{\frac{R H_{A M B}-97}{100}}
$$

In a composition of the desorption curves of all three fractions into one, we obtained picture 14, which demonstrates the two points which all three curves have in common. The first of them is $\mathrm{RH}_{\mathrm{AMB}}$ $97 \%$, when either finer fractions lose water from the surface and start to desiccate from the pore structure; the second is $\mathrm{RH}_{\mathrm{AMB}} 40.03$ $\%$, when the fractions no longer have any water to lose, and the desorption stops. It can further be seen from the curves that there are just slight deviations between the different fractions contrary to what one may expect from the finer fractions (a higher SSA). Here we have to realize that with increasing the SSA, the bulk density and contact area between the particle surfaces also rise. Figure 15 shows the rate of desorption. It is obvious that the finer fractions lose water more rapidly, especially at a higher degree of the RH of the environment, which most likely relates somehow to their fineness and open pore structure or to the surprising finding that they operate

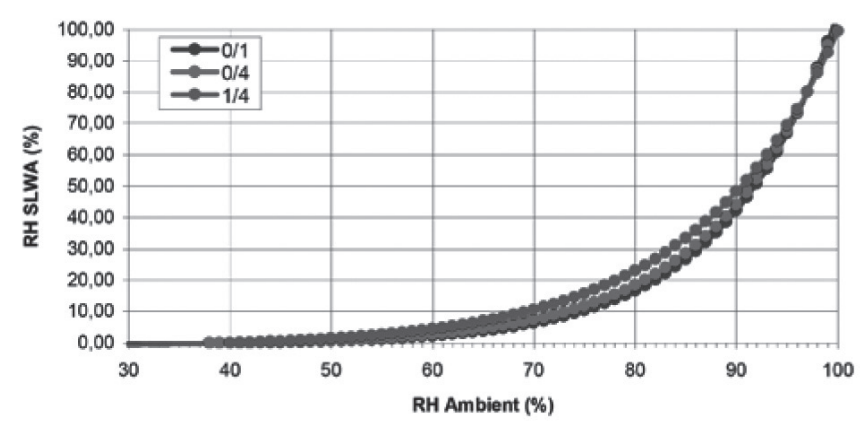

Fig. 14 Composition of all three desorption curves.

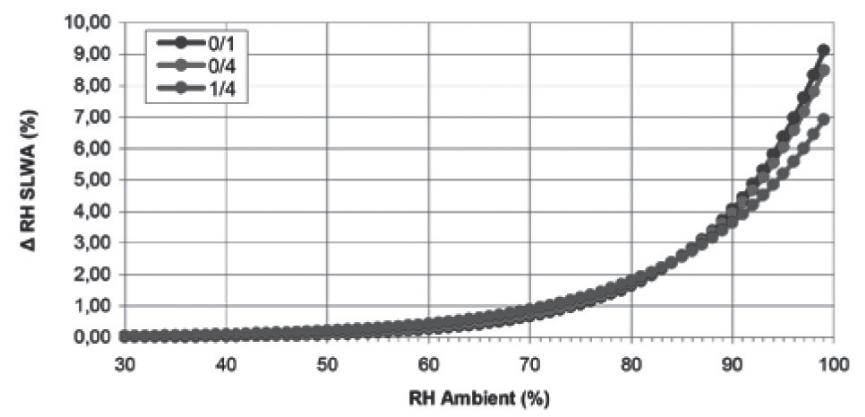

Fig. 15 Rate of desorption between two subsequent per cent degrees of $R H_{A M B}$.

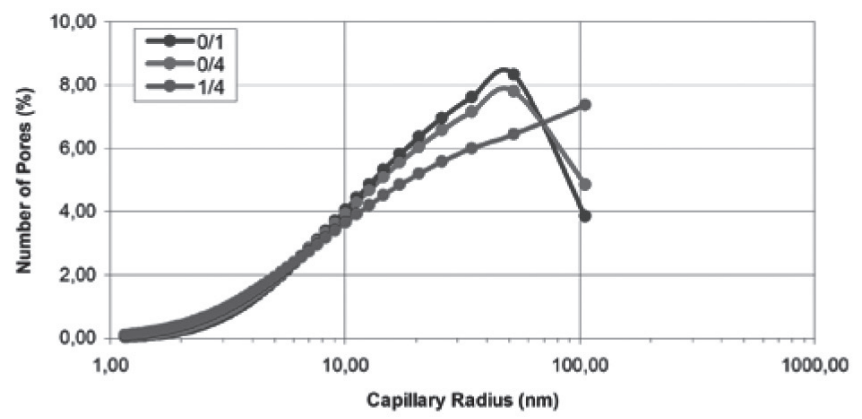

Fig. 16 Pore size distribution curves.

with a higher relative number of larger pores than the fraction $1 / 4$ as shown in Fig. 16.

\subsection{Suitability}

From a suitability point of view we cannot definitely state whether the tested fractions of the Liapor are or are not suitable to use in internal curing; moreover, it would also be irresponsible since we know several mechanisms of shrinkage against which we may effectively use Liapor. If we compare the desorption curves of Liapor with the one presented in fig. 3, we can see that the Liapor releases capillary water later; therefore, voids in the cement paste can be created, and the rising capillary tension may impose defects in the cement matrix. On the other hand, a delay in starting the release of water means that a higher amount of water will be available inside the cement paste later.

Nevertheless, Liapor has too few big pores (effective at very early ages), as can be seen from picture 17 . We can see that only around $50 \%$ of the pores have a radius greater than $10 \mathrm{~nm}$ (corresponding to $\mathrm{RH}_{\mathrm{AMB}}$ circa $90 \%$ ). As indicated in picture 18 , the Liapor is probably not suitable for internal curing at very

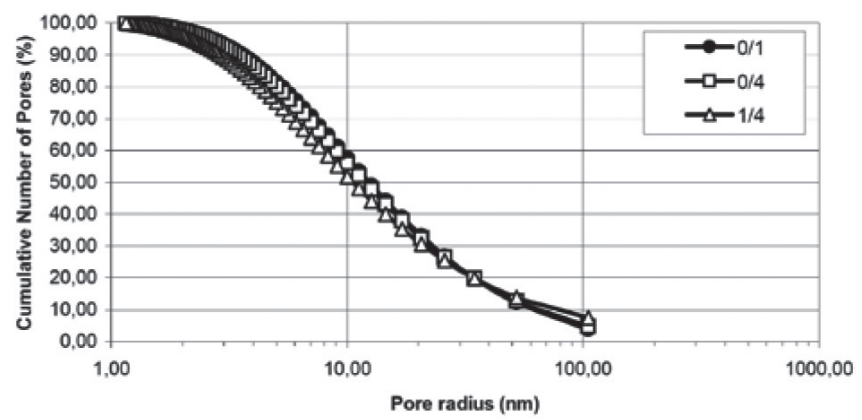

Fig. 17 Cumulative pore size distribution curves. 
early ages, but may be quite effective if it would start acting after 24 hours and if the concrete could be cured some other way until that time. Here it must be noted that other means of conventional curing such as watering, fogging, etc., are more appropriate at this stage of the concrete's maturity because its density rises as a function of time.

\section{CONCLUSIONS}

From the results of the desorption and other performed tests, we derived a desorption model for LWA Liapor. This may serve when deciding whether to use IC or not and, if so, how to design the mixture's composition. The LWA available on the European market quantitatively shows different behavior in comparison to the U.S. one and surprisingly contains fewer big pores, which shifts its action time further to a lower degree of RH. These findings tell us not to rely too much on IC at very early ages when using Liapor. Its benefits, in the form of the release of capillary water, starts when the capillary pressure $\mathrm{P}_{\mathrm{CAP}}$ reaches values (roughly $10 \mathrm{MPa}$ ) equal to $\mathrm{RH}$ around $95 \%$ (when the curves in fig. 17 reach the point of inflection). In conclusion, Liapor may be used in IC, but no earlier

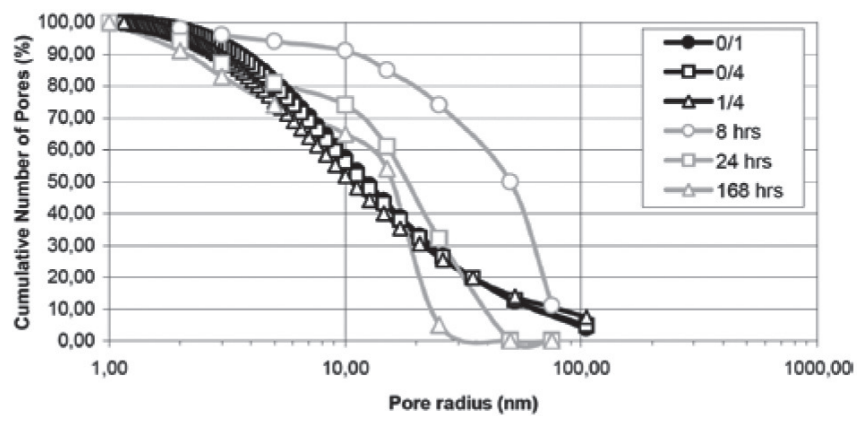

Fig. 18 Cumulative pore size distribution curves of SLWA vs. cement paste at different ages.

than after one day and preferably in concretes that are not too dense (of lower strengths). The desorption model derived may assist in the design of internal curing.

\section{Acknowledgments}

We would like to thank to LIAS Vintirov, k.s., for its material support of this work. We are also grateful to representatives of the Building Testing \& Research Institute, who let us use their facilities.

\section{REFERENCES}

[1] Adamson, A.W., Gast, A.P.: Physical Chemistry of Surfaces, $6^{\text {th }}$ Ed. Wiley-Interscience, New York, 1997.

[2] Bentz, D.P., Lura, P.: Mixture proportioning for internal curing, Concrete International, Vol. 27, ACI, pp: 35-40.

[3] Briatka, P.: Internal Curing of Concrete Using Lightweight Aggregate, In: Proceedings of conference on Design, Preparation and Execution of Constructions, held in Bratislava, March 2010.

[4] Briatka, P.: Reduction of Plastic Shrinkage Cracking in Concrete Pavements and Elimination of Maintenance Expenses, In: Proceedings of The Young European Arena of Research, Forum of European National Highway Research Laboratories, 2010.

[5] Briatka, P., Makýš, P.: Elimination of Plastic Shrinkage Cracking in Concrete, In: Proceedings of Junior Scientist Conference held in Vienna, April, 2010.
[6] Briatka, P., Makýšs, P.: Fresh Concrete Curing - Part 1: Water Loss from Concrete, In: Beton T.K.S., Vol. 10, No. 1, Beton TKS, Prague, 2010.

[7] Henkensiefken, R.: Internal Curing in Cementitious Systems Made Using Saturated Lightweight Aggregate, Master's Thesis, Purdue University, West Lafayette, IN, USA, 2008.

[8] Henkensiefken, R., Briatka, P., Bentz, D., Nantung, T., Weiss, J.: Plastic Shrinkage Cracking in Internally Cured Mixtures Prewetted Lightweight Aggregate Can Reduce Cracking, In: Concrete International, Vol.: 32, No. 2, ACI, 2010.

[9] Lura, P.: Autogenous Deformation and Internal Curing of Concrete, PhD. Thesis, Delft University, Delft, 2003.

[10] Radlinska, A., et. al.: Shrinkage Mitigation Strategies in Cementitious Systems: A Closer Look at Differences in Sealed and Unsealed Behavior, In: Journal of the Transportation Research Board, Washington, 2008. 


\section{REFERENCES}

[11] Sant, G., Eberhardt, A., et al.: The influence of shrinkage reducing admixtures (SRAs) on moisture absorption in cementitious materials at early-ages, Journal of Materials in Civil Engineering, Vol. 22, No. 3, 2010, pp. 277-286.

[12] Wittmann, F.H.: On the Action of Capillary Pressure in Fresh Concrete, In: Cement and Concrete Research, Vol. 6, No. 1, 1976.

[13] EN 12620+A1:2008 - Aggregates for concrete.

[14] EN 13055-1:2002 - Lightweight aggregates. Lightweight aggregates for concrete, mortar and grout.
[15] EN 1097-3:1998 - Tests for mechanical and physical properties of aggregates. Determination of loose bulk density and voids.

[16] EN 1097-6:2000 - Tests for mechanical and physical properties of aggregates. Determination of particle density and water absorption.

[17] EN 933-1:1997 - Tests for geometrical properties of aggregates. Determination of particle size distribution. Sieving method. 